\title{
Instagram Shopping in Saudi Arabia: What Influences Consumer Trust and Purchase Decisions?
}

\author{
Taghreed Shaher Alotaibi ${ }^{1}$, Afnan Abdulrahman Alkhathlan ${ }^{2}$, Shaden Saad Alzeer ${ }^{3}$ \\ College of Computing and Information Technology \\ Shaqra University, Riyadh, Saudi Arabia
}

\begin{abstract}
The recent developments of social networking sites (SNSs), along with the increasing usage of online shopping, has led to the emergence of social commerce platforms. Social commerce (s-commerce) is the use of Web 2.0 technologies and social media to deliver e-commerce services for consumers. The Kingdom of Saudi Arabia (KSA) has been witnessing a rapid growth in s-commerce usage, with Instagram being the most popular networks in the region. This paper is one of the few that investigates the factors affecting consumers' trust and purchase intentions in Instagram as a s-commerce platform in Saudi Arabia. The proposed model explores a number of factors, such as Social Media Influencers (SMIs), Key Opinion Leaders (KOLs) and consumer feedback, in terms of their influence on consumers' trust and purchase decisions. In addition to the effect of Maroof, which is an e-service provided by the Saudi Ministry of Commerce and Investment to evaluate the reliability of online stores. Following a quantitative approach and using Partial Least Squares Modeling (PLS-SEM), findings of this study revealed a positive relationship between consumers' trust and their purchase intentions. Additionally, the impact of SMIs and consumer feedback was shown to increase consumers' trust, in turn affecting intent to buy from Instagram stores, while the effect of Maroof and KOLs was shown to directly influence consumers' purchase intentions.
\end{abstract}

Keywords-Social commerce; instagram; trust; purchase intentio; maroof; key opinion leader; social media influencers

\section{INTRODUCTION}

The emergence of social media and Web 2.0 technology has enormously transformed people's lives, creating new ways to connect, collaborate and socialize. and with the increasing usage of smart devices, there has been a notable shift toward online shopping, which allows the enjoyment and convenience of home delivery and time-saving benefits. Recently, an emerging subset of e-commerce called social commerce (scommerce) has come to the fore, wherein SNSs are used as online markets. The combination of SNSs and e-commerce into s-commerce has changed the game for both the seller and the buyers; the shopping experience is no longer just a click away. Consumers are now actively engaging in the full shopping journey, from exploring products and comparing prices to making purchases and affecting each other's decisions with opinions and recommendations, all while enjoying the social intimacy and bonding these networks provide [1].

Conversely, it is also becoming very common to see businesses and commercial brands launching their pages on SNSs such as Facebook, Twitter and Instagram, which create opportunities to promote their products and services as well as immediate bridges to reach and connect with their customers. A recent statistic by [2] revealed that over 25 million brands have an account on Instagram.

Instagram is one of most popular social networking platforms for visual sharing. With one billion active users monthly in 2019 [3], it has enormously changed the way people share their photos and videos. Instagram users in general are led mostly by millennial and post-millennial generations [2]. The growing popularity of Instagram has led to a rise in using it as a s-commerce platform, especially in Arab countries. According to the Northwestern University in Qatar, Instagram usage has overtaken Twitter usage in the regions of Saudi Arabia and different Arab countries such as Egypt, Lebanon, Tunisia and the United Arab Emirates. Moreover, a recent survey showed that Instagram is the social network most used by the e-commerce industry in the Middle East region at a rate of $77 \%$ [4]. Additionally, over a third of Instagram users have made purchases through their accounts. Approximately a third of them are interested in shopping and fashion [4], yet there is only a limited number of studies $[5][6][7]$ in the current literature that focus on Instagram as a s-commerce platform.

In recent years, Saudi Arabia has witnessed rapid growth in s-commerce usage. About $42 \%$ of online shoppers in Saudi Arabia have purchased from social media platforms [8], finding a great sense of assurance in that they can easily find other consumers' recommendations and experiences. They also perceive a higher sense of transparency when the store owner is active online [8]. Although Saudi people are among the most active users on Instagram [4], little research has been conducted on the use of s-commerce generally in Arab regions and more specifically in Saudi Arabia [9][10]. Therefore, this research will shed light on the adoption of Instagram in Saudi Arabia as a s-commerce platform. The study aims to gain a deeper understanding of how Saudi consumers make their purchasing decisions and what factors are affecting these decisions. These factors are SMIs, KOLs, consumer feedback and Maroof as a third party.

SMIs are those who have attained popularity through their participation and activities on social media. Their followers usually have a great sense of attachment and admiration toward their lifestyle and behaviors [11]. Even though business companies usually sponsor and pay for influencers' posts to advertise their products, SMIs are more credible and have greater impact on their followers compared to traditional advertisements [12]. Nearly $35 \%$ of people who use Instagram 
on a daily basis have made a decision to purchase a product recommended by an influencer [13]. KOLs, on the other hand, are those such as doctors, educators and business leaders who are perceived by the public as experts in a specific area of knowledge and are valued by their followers for their opinions and expertise [14][15]. KOLs are not necessarily active online, yet they are found to have a significant effect on consumers' trust and purchase intentions with respect to s-commerce platforms [7]. In addition, consumers tend to check comments and feedback shared by others on the services or products they buy online, so many s-commerce platforms provide features that allow consumers to write and share their experiences and opinions, which usually influence other shoppers' purchase decisions [16].

Furthermore, due to the lack of direct interaction in scommerce, trust is one of the fundamental issues in ecommerce in general and more recently in s-commerce [6]. Many research studies have been conducted on the relationship between consumers' trust in s-commerce and their purchase intentions [17][18][9][19]. The proposed model in this study aims to further investigate how trust and purchase intention are related among Saudi consumers. Moreover, this work takes into consideration the impact of the Maroof eservice. Created and supervised by the Ministry of Commerce and Investment in Saudi Arabia, Maroof is a free interactive platform where consumers rate and evaluate online stores based on their past experiences, which will affect consumer trust in registered stores. The service also benefits store owners, who can reach more customers. To our knowledge, this is the first study that considers Maroof as an impact factor on the trust and purchase intentions of Saudi consumers in scommerce. This work is proposed in the hope that it will provide a useful foundation for future s-commerce research in the region.

The reminder of the paper is organized as follows: first, scommerce and trust are defined as concepts through the current literature. Second, the proposed model is described along with each of the proposed hypotheses, followed by the research methodology and findings. Finally, the limitations and future directions for the research are discussed to conclude the paper.

\section{CONCEPTUAL FRAMEWORK}

\section{A. Social Commerce}

Social commerce is an important topic that emerged in 2007; researchers' focus on it has risen from 2009 to the present [20]. Yet one of the fundamental issues in s-commerce is the lack of a standard definition. Prior studies tried to make a clear definition from many perspectives, but there is still no agreed-upon definition. Esmaeili et al. [21] defined it as "an Internet-based commercial application that makes use of Web 2.0 technologies and social media, and it supports user-created content and social interactions." Turban et al. [22] made a broader definition of s-commerce which is "e-commerce transactions delivered via social media." Moreover, Han et al. [23] conducted a review of 22 definitions of s-commerce and constructed their own definition, stating, "social commerce is a new business model of e-commerce, which makes use of
Web 2.0 technologies and social media to support socialrelated exchange activities."

There are several perspectives that define s-commerce. Ecommerce applications are the basis s-commerce is built upon. In addition to Web 2.0 technologies, which led to the creation of social media and SNSs that facilitated the interaction between consumers and sellers, smartphones are considered one of the factors that have helped the growth of s-commerce [22]. It is estimated that $89 \%$ of the Saudi population uses the Internet, with $68 \%$ of active users on social media [24]. In terms of e-commerce, Saudi Arabia is considered the first country in the Middle East [4]. Seventy-nine percent of Saudi users search online to purchase services or products, and $64 \%$ of them made an online purchase [24]. In the context of Instagram, Saudi users are still the largest population in the Middle East, accounting for 13 million active users in 2018 [24]. Nevertheless, there have been a few studies that investigated the adoption of s-commerce in this country.

\section{B. Trust}

Trust is defined as "the willingness of a party to be vulnerable to the actions of another party based on the expectation that the other will perform a particular action important to the trustor, irrespective of the ability to monitor or control that other party" [25]. According to [26], trust in scommerce in general includes two dimensions: informationbased trust, which denotes consumers' trust in the information found in the s-commerce sites; and identification-related trust, which is the trust s-commerce consumers place in each other. As for the first dimension, many scholars have found that consumers' trust toward s-commerce sites significantly affect their purchase intention[27][28][29][18][19]. For the second dimension, [29] found that consumers' trust toward other members of the s-commerce platform increases their trust toward the platform itself and consequently, their purchase intention. On another note, the number of Instagram store followers was found to be a great indicator of legitimacy and therefore, trustworthiness of the seller. People tend to believe that the more followers a seller has, the more trustworthy he or she is [30]. Consumers' prior experience with a certain company does not necessarily contribute to their trust in the company's s-commerce site [26]. In addition, [18] examined the importance of trust in determining consumers' engagement in s-commerce. Based on the trust transfer theory [31], they studied multiple technical factors such as ratings, recommendations, forums and communities that affect consumers' perceived trust of s-commerce sites, and found a significant effect on consumers' trust and engagement. Similarly, the work by [18] found that social presence, familiarity and perceived sense of security were found to have the same positive effect on trust.

Prior research on trust in the s-commerce context mainly focused on either the psychological or the social aspects of customers that build their trustfulness, such as familiarity [18][17][19][5], enjoyment [10][17][5], and habit [10][5]; or the technical factors of an s-commerce site, such as information quality [10][32][9], perceived ease of use and perceived usefulness [9][27][5]. Yet little work has been done to investigate the effects of external factors on consumers' trust or purchase intention. For example, [7] studied the effect 
of KOLs and peer customer endorsements on trust and found that KOLs have a positive impact while customer endorsements have an insignificant one. However, their research needs more generalizability across different cultures.

\section{RESEARCH MODEL AND HYPOTHESIS DEVELOPMENT}

This study is will investigate the effect of a group of external factors such as Maroof e-service, SMIs, KOLs and consumer feedback on Instagram shopping in Saudi Arabia, in order to deeply understand the formation of consumers' trust and intention to purchase. The proposed research model is depicted in Fig. 1.

\section{A. Maroof}

Maroof is an e-service that aims to enhance the ecommerce sector in Saudi Arabia. It was created by the Ministry of Commerce and Investment in conjunction with Thiqah Business Services, the operator and developer of the platform. Maroof works as a platform that helps to evaluate online stores in Saudi Arabia, which will benefit both buyers and sellers at the same time. Online sellers registered with Maroof can reach more customers easily. Through the Maroof network, they can share their social networking accounts and contact information for their stores. Buyers who look for services or products can search for them using Maroof in an easy and trustworthy way. Moreover, buyers can browse ratings, reviews and other consumers' feedback in a store's page, to decide whether to buy from a given store. Also, consumers can rate stores depending on their experiences [33]. Consumer ratings and comments are checked for validity by Maroof team. All information shared on Maroof is highly secure, and all services and products provided by these stores are under the regulation of the Ministry of Commerce and Investment. The Maroof initiative started in 2016 and, a recent report from the ministry showed that in 2018, the number of stores registered on Maroof has reached 20,000. Registering on Maroof is free to encourage merchants to use it. Moreover, when a merchant creates a commercial registry, then he or she is awarded a special certificate from Maroof called a Golden Certificate. Most online stores in Saudi Arabia have an Instagram account, so they register on Maroof to become accredited. Since this service is under the ministry's control, it is mainly used as a way to enhance trust between buyers and sellers.

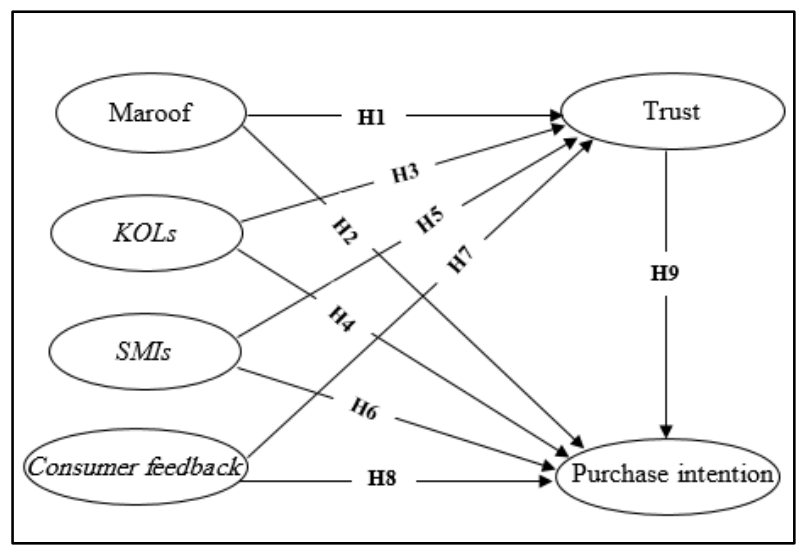

Fig. 1. Research Model.
This research considers Maroof as a special and unique factor that impacts Saudi consumers' trust and intentions to purchase from Instagram. To the best of our knowledge, this study is the first one that investigates the effect of Maroof on s-commerce in Saudi Arabia. Thus, it hypothesizes the following:

H1: Maroof e-service has a positive impact on consumers' trust.

H2: Maroof e-service has a positive impact on consumers' purchase intentions.

\section{B. Key Opinion Leaders (KOLs)}

KOLs represent a small portion of people who are deeply knowledgeable and skillful in a certain field [34]. Their superior levels of education, qualifications and social status empower them to influence their audience [35]. An opinion leader is an individual who greatly influences people's decisions, behaviors and attitudes [14]. They are either experts in a specific area of knowledge, or have a wide range of social connections [14]. Previous research has identified several characteristics of KOLs, namely that they are professionals, innovative, involved, and sociable [36]. Moreover, [37] demonstrated several characteristics in determining KOLs: they must be knowledgeable in their field, respected by their audience, have wider access to information sources than their followers, and lastly, have the ability to maintain their leadership. According to [36], KOLs can be generally categorized into two types: the ones who are active offline such as public figures and celebrities, and thus can easily become online opinion leaders. And those who share their opinions online exclusively.

However, there is some degree of overlap between the terms "social media influencer" and "key opinion leader." Both terms describe individuals who have the ability to impact people within their areas of interest. The main difference is that the KOL term extends to experts in particular fields such as technology, science, medicine and more. Also, they usually have profession parallel to their subjects of expertise, such as doctors, entrepreneurs or writers [38]. Their audience members are not necessarily fans of their personalities, but rather of their knowledge and expertise. On the other hand, SMIs are popular personalities on social media platforms such as Instagram, Snapchat, Facebook and YouTube. They have a large community of followers who greatly admire their lifestyles and personal choices [39].

KOLs are considered experts in their fields, and are usually asked for advice and recommendations [7]. In their work, [34] found a positive effect on marketing strategies caused by the strong relationship KOLs have with their followers. Instagram is the social platform most frequently used by opinion leaders [40]. Therefore, Instagram users heavily rely on KOLs' opinions and recommendations due to the lack of explicit measures of store ratings and reputations [7]. KOLs and consumer comments were found to be strong influencers of consumers' trust and thus their purchase intention in Indonesia [41]. Furthermore, [7] found that KOLs have a strong effect on consumers' trust toward an Instagram store. 
This work considers KOLs an important factor in determining consumers' trust in Instagram stores and distinguishes them from SMIs, who do not possess deep knowledge in a certain field. Thus, the following hypotheses are formed:

\section{H3: KOLs have a positive impact on consumer trust.}

H4: KOLs have a positive impact on consumer purchase intentions.

\section{Social Media Influencers (SMIs)}

In recent years, with the continually growing use of social media, a global marketing phenomenon called "influencer marketing," in which brands and business use social media figures to reach their target audience, has emerged to the forefront. SMIs are people who attained their popularity by generating and sharing content via social media platforms such as Instagram, Facebook, YouTube and Snapchat. SMIs usually focus on a certain field, such as healthy lifestyle, food, travel, beauty or fashion. Unlike KOLs, SMIs' audiences are nonspecific and usually interested in their online personas and lifestyles rather than their discipline of knowledge. SMIs usually advertise for products or services related to their own interests and lifestyles. Consumers tend to make their purchase decisions under the impact of the influencers' experience and recommendations [42]. Contrary to public celebrities who are well-known through traditional media channels such as TV and newspapers prior to the social media era [42], a study by [11] found that SMIs or the "Instafamous" are more admirable than traditional celebrities, and that consumers perceive them as more relatable and credible. Social media marketing is getting more attention and appreciation from consumers compared to traditional advertisements [12]. Companies pay influencers as part of their marketing strategies. Financial benefits are usually the main reason for influencers to adopt corporate marketing and vice versa. According to [43], the returns on investment (ROI) from influencer marketing is 11 times greater than what traditional advertisements make in a year.

Influencers have likable personalities and are more relatable than celebrities and public figures. They indulge their audiences in their personal lives and share their opinions and experiences with them, influencing their attitudes, ideas and decisions [12]. The author in [44] found that the more attached a consumer is to an influencer, the more driven he or she is to buy the products promoted by the influencer. A study by Twitter in 2016 revealed that consumers trust SMIs similarly as they trust their own friends or relatives, and $40 \%$ of them say that they have purchased an item online after seeing it used by an influencer on Twitter.

Influencer marketing is related to the halo effect theory described by [45], a cognitive bias wherein the perception of an individual is based upon a single trait or characteristic. Accordingly, brands are using influencers with positive halos to promote their products. This creates a positive association between the influencer and the product [11]. Hence, [46] revealed a positive correlation between influencers' content informative value and consumers' trust as well as their purchase intention. Moreover, the trustworthiness of influencers and their attractiveness and similarity to their followers have significant effects on the followers' trust in their sponsored content. Another study by [44] investigated the persuasion cues of Instagram and YouTube fashion and beauty influencers in France. They found that the credibility of a given influencer positively impacts the purchase intention of his or her target audience. In addition, [47] investigated how influencers' credibility, physical attractiveness, promotedproducts congruency and meaning transfer affect the purchase intentions of their followers. Their findings revealed that credibility and physical attractiveness failed to affect consumers' purchase intentions, while there were strong relationships between product match-up and meaning transfer with purchase intentions.

However, research on influencer marketing is still insufficient. The work by [15] contributes to a deeper understanding of how SMIs affect consumer behavior and decisions. The focus of this study is limited to Instagram influencers due to the popularity and ongoing growth of Instagram as an s-commerce platform. Hence, this study hypothesizes:

\section{H5: SMIs have a positive impact on consumers' trust.}

H6: SMIs have a positive impact on consumers' purchase intentions.

\section{Consumer Feedback}

Despite the increasing usage of online shopping, consumers still experience some uncertainty when making purchase decisions. This is mainly because all products provided by online stores are displayed merely as pictures with a little description. These pictures do not necessarily reflect the real quality or condition of these products. In order to solve this dilemma, most e-commerce platforms have added a variety of technical features that allow consumers to share their experiences with their purchased products. These features can vary from ratings, reviews and recommendations to forums, communities [1] and comments[48]. Consumers usually search for peer reviews and ratings before making purchase decisions because they tend to believe more in consumer experiences rather than the information posted by the business itself [19].

Moreover, several studies showed that consumer feedback, whether a review or a comment on a website or in a community, has a positive impact on consumers' trust. For instance, [16] studied the features provided by Web 2.0 technologies that encourage user participation in online interactions. The study aimed to investigate how the social interaction between consumers increases trust toward a specific vendor. They built a model for the social constructs of forums and communities, recommendation and referrals and ratings and reviews. Their findings showed that s-commerce constructs are essential to influencing customer trust. Furthermore, [48] found that consumers' trust toward a scommerce site is influenced by the information generated by that site's consumers, which in turn increases their purchase intentions.

In the context of Instagram, consumers have the ability to write their honest opinions on a store's page, so other 
customers can see the comments and decide whether to buy from the store. In addition, some Instagram store owners can share testimonials from their previous customers as posts or by using the highlight feature. The study [41] demonstrated that trust and purchase intention are influenced by consumer feedback. Nevertheless, a few studies have been conducted to investigate the effect of consumer feedback. This study considers consumer feedback as an important factor that affects trust and purchase intention and hypothesizes the following:

H7: Consumer feedback on an Instagram store positively impacts trust.

H8: Consumer feedback on an Instagram store positively impacts purchase intentions.

\section{E. Trust and Purchase Intention}

Due to the lack of physical contact between vendors and consumers, uncertainty is the dominant sense in s-commerce [16]. Consumers tend to rely on each other's reviews, ratings and recommendations in their decision-making processes to establish their trust in a specific vendor or site. Therefore, trust plays a crucial role in the s-commerce context.

Purchase intention is the willingness of an individual to make purchases from a s-commerce platform [19]. Previous studies demonstrated that customers' intent to purchase from a specific store is highly dependent on their trust in that store [18][7][19]. Furthermore, [5] identified trust as a significant factor in influencing consumer purchase intentions on scommerce sites. Prior studies [27][28][29] consistently revealed a strong positive correlation between a consumer's trust and his or her intent to purchase. Aligned with these studies, the following hypothesis is proposed.

H9: Consumers' trust toward an Instagram store positively impacts their purchase intentions.

\section{RESEARCH METHODOLOGY}

\section{A. Sample and Data Collection}

This study was designed to investigate the impact of Maroof e-service, SMIs, KOLs and consumer feedback on the trust and purchase intentions of consumers. An online survey was built to collect responses from Instagram users. To maximize the number of participants, a link for the survey was distributed over different social media platforms such as Instagram, Telegram, WhatsApp and Twitter as well as by email. Because the study targeted only Instagram, this was highlighted at the beginning of the survey to make sure participants understand the target sample. Furthermore, since the study targeted Saudi users, the survey was translated into Arabic before distribution. As a result, 225 complete responses were received. Responses were not missing for any of the survey items.

Based on the critical Mahalanobis distance [49], nine outliers were identified and removed from the respondents' sample, so a total of 216 valid responses were used in the analysis. The study included more females than males $(75.5 \%$ vs. $24.5 \%$ ). Various age groups were represented in the study sample (Table I). Regarding education, most participants $(71.3 \%)$ had a bachelor's degree, $12 \%$ completed high school, $4.63 \%$ had a diploma, and $12 \%$ had a postgraduate degree.

\section{B. Measures}

The survey was built using a five-point Likert scale from 1 $=$ strongly disagree, $2=$ disagree, $3=$ neutral, $4=$ agree to $5=$ strongly agree. Two academic faculty members participated in this study to check and correct the survey questions before they were distributed. These faculty members were familiar with s-commerce and statistical techniques (Table II).

TABLE. I. Descriptive Statistics of The Study SAMPLE

\begin{tabular}{|l|l|}
\hline & N=216 \\
\hline Fex: & \\
\hline Male & $163(75.5 \%)$ \\
\hline Age: & $53(24.5 \%)$ \\
\hline 18 or less & \\
\hline $19-25$ & $13(6.02 \%)$ \\
\hline $26-30$ & $82(38.0 \%)$ \\
\hline$>30$ & $53(24.5 \%)$ \\
\hline Education: & $68(31.5 \%)$ \\
\hline High school or lower & \\
\hline Bachelor's degree & $26(12.0 \%)$ \\
\hline Diploma & $154(71.3 \%)$ \\
\hline Postgraduate & $10(4.63 \%)$ \\
\hline
\end{tabular}

\section{ANALYSIS}

PLS-SEM analysis was performed using the SEMinR package, which is used to create and estimate structural equation models using partial least squares path modeling (PLS-PM or PLS-SEM). Advantages of PLS-SEM over conventional covariance-based structural equation modeling (CB-SEM) include that it can handle small sample sizes and is suitable for exploratory and confirmatory research [50]. It also uses the bootstrap (resampling) approach to compute standard errors, $\mathrm{p}$ values and confidence intervals. The present study used 200 resamples to assess path significance and calculate the $95 \%$ confidence intervals. Hypothesis testing was performed at a $5 \%$ level of significance. Goodness of fit was assessed using $\mathrm{R}^{2}$ for the dependent variables included in the analysis (trust and purchase intention).

\section{A. Reliability}

Reliability is a measure of internal consistency in a questionnaire (i.e., how coherent items of the same scale are, or how closely they are correlated) [51]. Cronbach's Alpha $(\alpha)$ and composite reliability (rhoC or CR) were two methods used to assess the reliability of the six factors in this study [52]. Reliability assessment using Cronbach's $\alpha$ and composite reliability showed that the factors included in the analysis were reliable as demonstrated by values $>0.7$ for all scales (Table II). 
TABLE. II. SOURCES OF CONSTRUCTS, RELIABILITY AND VALIDITY

\begin{tabular}{|c|c|c|c|c|c|}
\hline Code & Scales & $\begin{array}{l}\text { Factor } \\
\text { loading }\end{array}$ & $\mathbf{C R}$ & AVE & $\begin{array}{l}\text { Cronbach's } \\
\alpha\end{array}$ \\
\hline & Maroof $\boldsymbol{e}$-service $(\boldsymbol{M})(\mathrm{New})$ & & 0.817 & 0.536 & 0.77 \\
\hline M1 & Maroof e-service is a trusted platform that protects shopper interests. & 0.755 & & & \\
\hline M2 & I trust Instagram store that has a Maroof certificate. & 0.922 & & & \\
\hline M3 & I check Instagram store's page on Maroof e-service to see customers' comments about the store. & 0.547 & & & \\
\hline \multirow[t]{2}{*}{ M4 } & I search for Instagram stores that have a high rate on Maroof e-service page. & 0.651 & & & \\
\hline & Social media influencer (SMI) (Adopted and adjusted from [7] [56]) & & 0.91 & 0.718 & 0.86 \\
\hline SMI1 & I feel that social media influencers are generally trustworthy & 0.867 & & & \\
\hline SMI2 & I feel that recommendations by social media influencers are generally reliable. & 0.905 & & & \\
\hline SMI3 & I'm more likely to try a new product if my favorite influencer recommends it. & 0.787 & & & \\
\hline \multirow[t]{2}{*}{ SMI4 } & I believe that social media influencers have my best interests in mind. & 0.826 & & & \\
\hline & Key opinion leaders (KOL) (Adopted and adjusted from [7] [56] [44]) & & 0.928 & 0.719 & 0.9 \\
\hline KOL1 & I find that KOLs are experts in their domain. & 0.788 & & & \\
\hline KOL2 & I feel that KOLs are generally trustworthy. & 0.84 & & & \\
\hline KOL3 & I feel that recommendations by KOLs are generally reliable. & 0.902 & & & \\
\hline KOL4 & I'm more likely to try a new product if a KOL recommends it. & 0.847 & & & \\
\hline \multirow[t]{2}{*}{ KOL5 } & I believe that KOLs have my best interests in mind. & 0.861 & & & \\
\hline & Consumer Feedback (CF) (Adopted and adjusted from [7] [56]) & & 0.851 & 0.54 & 0.78 \\
\hline CF1 & Instagram stores display testimonials from satisfied customers. & 0.642 & & & \\
\hline $\mathrm{CF} 2$ & $\begin{array}{l}\text { I can see from the comments in an Instagram store that existing customers are satisfied with the } \\
\text { store. }\end{array}$ & 0.736 & & & \\
\hline $\mathrm{CF} 3$ & I feel Instagram users' comments are generally honest. & 0.855 & & & \\
\hline $\mathrm{CF} 4$ & I feel Instagram users' comments are reliable. & 0.853 & & & \\
\hline \multirow[t]{2}{*}{ CF5 } & I usually check customers' comments in Instagram stores before making a purchase. & 0.534 & & & \\
\hline & Trust $(\boldsymbol{T})$ (Adopted and adjusted from [7]) & & 0.884 & 0.657 & 0.83 \\
\hline $\mathrm{T} 1$ & Instagram shopping is generally trustworthy. & 0.824 & & & \\
\hline $\mathrm{T} 2$ & I trust information on Instagram to be true. & 0.839 & & & \\
\hline $\mathrm{T} 3$ & I think that Instagram stores will not do anything to take advantage of their customers. & 0.751 & & & \\
\hline \multirow[t]{2}{*}{$\mathrm{T} 4$} & I feel comfortable making purchases from Instagram stores. & 0.824 & & & \\
\hline & Purchase Intention (PI) (Adopted and adjusted from [7] [57]) & & 0.907 & 0.764 & 0.85 \\
\hline PI1 & I would seriously contemplate buying from Instagram. & 0.904 & & & \\
\hline PI2 & I am likely to make future purchases from Instagram. & 0.847 & & & \\
\hline PI3 & I intend to purchase products or services from Instagram whenever I need to shop. & 0.87 & & & \\
\hline
\end{tabular}

Notes: CR, composite reliability; AVE, average variance extracted; $\alpha$ Alpha

\section{B. Validity}

To check the validity of this research, construct validity was tested. Construct validity can be assessed by discriminant and convergent validity [53].

Convergent validity was examined through loadings (correlations) of manifest variables on the corresponding latent variables. Loading should be equal to or greater than 0.5 . The average variance extracted (AVE) was also used to assess convergent validity. Values greater than 0.5 were considered satisfactory [54]. All scales scored > 0.5 (Table II), indicating that convergent validity can be assumed.
Discriminant validity was assessed by examining the correlation between factors. The correlation between any two factors should not exceed 0.7 and should not exceed $\sqrt{A V E}$. For each factor, $\sqrt{A V E}$ was higher than its correlation with all remaining factors (Table III). This indicates that discriminant validity was met.

A further assessment to test the discriminant validity is checking the factor loading of each indicator. Cross-loadings were also examined to ensure that none of the items were loaded on more than one factor (Table IV). Factor loadings were greater than 0.7 for all items (which is considered ideal) except for M3 and CF5. However, removing these items from 
the model did not alter the final model results. Thus, it was decided to keep them in the model as they did not cross-load on any other factors and had a loading $>0.5$, which is considered acceptable [55]. The AVE was $>0.5$ for all factors, which was another reason to keep these items in the model (Table II).

TABLE. III. CORRELATION BETWEEN FACTORS

\begin{tabular}{|l|l|l|l|l|l|l|}
\hline & SMI & CF & M & KOL & T & PI \\
\hline SMI & 0.847 & & & & & \\
\hline CF & 0.212 & 0.734 & & & & \\
\hline M & 0.011 & 0.305 & 0.732 & & & \\
\hline KOL & 0.178 & 0.16 & 0.143 & 0.848 & & \\
\hline T & 0.517 & 0.391 & 0.12 & 0.19 & 0.81 & \\
\hline PI & 0.352 & 0.288 & 0.235 & 0.243 & 0.649 & 0.87 \\
\hline
\end{tabular}

Notes: Numbers on the diagonal (highlighted) are the $\sqrt{ }$ AVE. Other numbers represent the correlations between factors

TABLE. IV. CROSS LOADINGS

\begin{tabular}{|l|l|l|l|l|l|l|}
\hline & $\mathrm{M}$ & $\mathrm{SMI}$ & $\mathrm{KOL}$ & $\mathrm{CF}$ & $\mathrm{T}$ & $\mathrm{PI}$ \\
\hline M1 & 0.755 & -0.043 & 0.117 & 0.187 & 0.02 & 0.132 \\
\hline M2 & 0.922 & -0.022 & 0.128 & 0.277 & 0.13 & 0.262 \\
\hline M3 & 0.547 & 0.052 & 0.12 & 0.153 & -0.016 & 0.01 \\
\hline M4 & 0.651 & 0.125 & 0.094 & 0.248 & 0.104 & 0.1 \\
\hline SMI1 & 0.023 & 0.867 & 0.079 & 0.201 & 0.48 & 0.286 \\
\hline SMI2 & -0.003 & 0.905 & 0.113 & 0.212 & 0.481 & 0.28 \\
\hline SMI3 & -0.016 & 0.787 & 0.224 & 0.094 & 0.34 & 0.356 \\
\hline SMI4 & 0.033 & 0.826 & 0.2 & 0.203 & 0.441 & 0.279 \\
\hline KOL1 & 0.114 & 0.053 & 0.788 & 0.078 & 0.05 & 0.128 \\
\hline KOL2 & 0.111 & 0.153 & 0.84 & 0.121 & 0.155 & 0.168 \\
\hline KOL3 & 0.132 & 0.163 & 0.902 & 0.108 & 0.198 & 0.244 \\
\hline KOL4 & 0.117 & 0.164 & 0.847 & 0.218 & 0.15 & 0.241 \\
\hline KOL5 & 0.132 & 0.174 & 0.861 & 0.127 & 0.195 & 0.207 \\
\hline CF1 & 0.31 & 0.113 & 0.166 & 0.642 & 0.209 & 0.273 \\
\hline CF2 & 0.266 & 0.204 & -0.015 & 0.736 & 0.267 & 0.141 \\
\hline CF3 & 0.196 & 0.189 & 0.099 & 0.855 & 0.348 & 0.215 \\
\hline CF4 & 0.174 & 0.214 & 0.165 & 0.853 & 0.404 & 0.242 \\
\hline CF5 & 0.242 & -0.009 & 0.185 & 0.534 & 0.119 & 0.185 \\
\hline T1 & 0.172 & 0.363 & 0.122 & 0.302 & 0.824 & 0.553 \\
\hline T2 & 0.082 & 0.384 & 0.141 & 0.38 & 0.839 & 0.502 \\
\hline T3 & -0.072 & 0.455 & 0.189 & 0.252 & 0.751 & 0.371 \\
\hline T4 & 0.169 & 0.474 & 0.169 & 0.326 & 0.824 & 0.64 \\
\hline PI1 & 0.218 & 0.362 & 0.2 & 0.313 & 0.621 & 0.904 \\
\hline PI2 & 0.195 & 0.245 & 0.247 & 0.153 & 0.465 & 0.847 \\
\hline PI3 & 0.203 & 0.304 & 0.199 & 0.271 & 0.599 & 0.87 \\
\hline
\end{tabular}

\section{FINDINGS}

PLS-SEM provided enough evidence to support $\mathrm{H} 2, \mathrm{H} 4$, $\mathrm{H} 5, \mathrm{H} 7$ and $\mathrm{H} 9$ but not enough evidence to support $\mathrm{H} 1, \mathrm{H} 3$, H6 and H8. (Table V) shows that Maroof certification was directly associated with higher purchase intention $(\beta=0.152$, $\mathrm{P}<0.05)$. This indicates that intent to purchase from an Instagram score increases by 0.152 points for each 1-point increase in trust in Maroof. Also, KOLs were directly associated with higher purchase intentions $(\beta=0.105, \mathrm{P}<$ $0.05)$, indicating that purchase intention score increases by 0.105 points for each 1-point increase in trust in KOLs. In contrast, the SMI factor was associated with higher trust in Instagram $(\beta=0.446, P<0.001)$. This indicates that consumers' trust scores increase by 0.446 points for each 1 point increase in their trust in SMIs. Similarly, consumer feedback was associated with higher trust $(\beta=0.28, \mathrm{P}<$ 0.001 ), indicating that trust in Instagram shopping score increases by 0.28 points for each 1 -point increase in trust in consumer feedback. Lastly, trust in Instagram was associated with higher purchase intentions $(\beta=0.607, \mathrm{P}<0.001)$. This indicates that the purchase intention increases by 0.607 points for each 1-point increase in trust.

Although there were no statistically significant direct effects of SMIs and consumer feedback on purchase intention (H6 and H8), mediation analysis showed that there was a statistically significant indirect effect (through trust) for SMIs on purchase intention $(\beta=0.267, \mathrm{P}<0.001)$, and there was a statistically significant indirect effect (through trust) for consumer feedback on purchase intention $(\beta=0.17, \mathrm{P}<$ $0.001)$.

The model's goodness of fit was assessed by examining the proportion of variance in trust and purchase intention from Instagram stores that was explained by the independent variables (IVs). Examining the adjusted $\mathrm{R}^{2}$ for trust and purchase intention revealed that the four IVs (Maroof, KOLs, SMIs and consumer feedback) explained $34.3 \%$ of the variability in trust. The four IVs and trust combined explained $44.5 \%$ of the variability in the purchase intention. Furthermore, the research tested three control variables (sex, education and gender), but none of them had significant effects on purchase intention or trust.

TABLE. V. PLS-SEM PATH COEFFICIENTS

\begin{tabular}{|l|l|l|l|l|l|}
\hline H & Path & $\beta$ & LLCI & ULCI & P \\
\hline H1 & M -> T & 0.02 & -0.093 & 0.157 & $>0.05$ \\
\hline H2 & M -> PI & $\mathbf{0 . 1 5 2}$ & $\mathbf{0 . 0 3 1}$ & $\mathbf{0 . 2 6 6}$ & $<\mathbf{0 . 0 5}$ \\
\hline H3 & KLO -> T & 0.063 & -0.055 & 0.168 & $>0.05$ \\
\hline H4 & KLO -> PI & $\mathbf{0 . 1 0 5}$ & $\mathbf{0 . 0 1 4}$ & $\mathbf{0 . 2 1 5}$ & $<\mathbf{0 . 0 5}$ \\
\hline H5 & SMI -> T & $\mathbf{0 . 4 4 6}$ & $\mathbf{0 . 3 5 7}$ & $\mathbf{0 . 5 4 4}$ & $<\mathbf{0 . 0 0 1}$ \\
\hline H6 & SMI -> PI & 0.021 & -0.089 & 0.145 & $>0.05$ \\
\hline H7 & CF -> T & $\mathbf{0 . 2 8}$ & $\mathbf{0 . 1 8 2}$ & $\mathbf{0 . 3 8 1}$ & $<\mathbf{0 . 0 0 1}$ \\
\hline H8 & CF -> PI & -0.017 & -0.121 & 0.096 & $>0.05$ \\
\hline H9 & T -> PI & 0.607 & 0.457 & 0.701 & $<0.001$ \\
\hline \multicolumn{7}{|l}{ LLCI: Bootstrapped lower 95\% confidence interval, ULCI: Bootstrapped upper 95\% confidence } \\
interval, H: Hypothesis, $\beta$ : Estimate
\end{tabular}




\section{VII.DISCUSSION}

This research sought to investigate the factors influencing consumers' purchase intentions from Instagram in Saudi Arabia. PLS-SEM was used to test the proposed model. Our findings demonstrated that the proposed model had a good validity and reliability as well as a good predictive power. All four independent variables (Maroof, KOLs, SMIs and consumer feedback) affected consumers' purchase intentions. However, these variables exerted their effects through different pathways. Maroof and KOLs directly affected consumers purchase intentions. Their indirect effects on purchase intention (through the mediator trust) were not statistically significant. Thus, the effects of Maroof and KOLs on purchase intention are entirely direct. However, this result is slightly different than the studies [41][7] which found that KOLs directly influences consumers trust.

The exact opposite was observed with SMIs on purchase intention, whose direct effect was not statistically significant. This is in line with [48] but differs from [44] which found that SMIs credibility significantly affect their followers' purchase intentions. Similarly, consumer comments direct effect was on trust but not on purchase intentions. This result is different than the one by [42] which found that comments influences purchase intentions directly, while the one by [7] revealed that consumers comments do not directly affect their trust. However, the indirect effects of both SMIs and consumers feedback on purchase intention (through the mediator trust) were statistically significant. These results show that the effect of SMIs and consumer feedback on purchase intention is solely indirect.

Overall, the research indicates that the above factors statistically influence individuals' trust and purchase intention. Consistent with and in addition to previous studies [19][7][5][28][29], our findings revealed that trust is associated with higher purchase intentions.

\section{CONCLUSION}

This study proposed a new model to study the factors influencing consumers shopping on Instagram in Saudi Arabia. The model consists of the Maroof e-service, SMIs, KOLs, and consumer feedback and how they influence consumer trust and purchase intention. The study's contribution to the s-commerce field is by studying these factors combined. To our knowledge, this study is the first study to investigate the effect of the Maroof e-service and jointly analyze the influence of SMIs and KOLs on consumer trust and purchase intention.

Moreover, these research findings can help vendors, whether they are individuals or companies, to understand the important factors that influence their customers' purchase intentions to maximize their profits. We found that an Instagram store with a Maroof certificate will enjoy higher purchase intentions from consumers. Likewise, choosing the appropriate KOLs to advertise or recommend products will positively influence consumers' intent to buy. Meanwhile, SMIs were found to be positively related to consumers' trust in Instagram stores. Previous consumers' comments and feedback were also found to have the same positive effect on building consumer trust.

\section{LIMITATIONS AND FUTURE DIRECTIONS}

The aim of this study was to investigate the effects of different factors on consumer trust and purchase intention in the context of Saudi Arabia, and it is not without limitations. First, the proposed model was tested on the Instagram network only due to its high popularity in Saudi Arabia. Future studies could experiment on other social networks such as Twitter and Facebook as well. Second, the number of respondents was relatively small and the majority of them were females, so these results might be biased. It is hoped that future studies will enlarge their sample sizes to reflect the actual numbers of Saudi Instagram users. Furthermore, the targeted sample of this study was limited to the Saudi population. Hence, these findings might not be generalizable across different cultures. Third, this study investigated a limited number of factors. More factors, such as previous purchase experience and store reputation, could be examined in the future to measure their influence on consumer trust. Finally, although this study followed a quantitative approach and the proposed model had a good validity and reliability, we recommend that future studies use qualitative measures such as content analysis and participant observations, which might offer a deeper understanding of how consumers actually build their trust and make purchase decisions.

\section{REFERENCES}

[1] N. Hajli and J. Sims, "Social commerce: The transfer of power from sellers to buyers," Technol. Forecast. Soc. Change, vol. 94, pp. 350-358, 2015.

[2] K. Smith, "49 Incredible Instagram Statistics,” 2019.

[3] Statista, "Social Media Usage Worldwide," 2019.

[4] Crowd Analyzer, "State of Social Media 2018," 2018.

[5] I. Ben Yahia, N. Al-Neama, and L. Kerbache, "Investigating the drivers for social commerce in social media platforms: Importance of trust, social support and the platform perceived usage," J. Retail. Consum. Serv., vol. 41, no. September 2017, pp. 11-19, 2018.

[6] S. Abed, "An empirical examination of Instagram as an s-commerce channel,” J. Adv. Manag. Res., vol. 15, no. 2, pp. 146-160, 2018.

[7] J. W. S. Che and C. M. K. Cheung, "Consumer Purchase Decision in Instagram Stores: The Role of Consumer Trust," in Proceedings of the 50th Hawaii International Conference on System Sciences, pp. 24-33, 2017.

[8] C. and I. T. Commission, "ICT Report: E-Commerce in Saudi Arabia," 2017.

[9] M. Aldhahery, M. R. Wahiddin, M. A. Khuhro, and Z. A. Maher, "Investigation of Adoption Behaviour for Social Commerce in the Kindom of Saudi Arabia," in Proceedings 2018 IEEE 5th International Conference on Engineering Technologies and Applied Sciences, ICETAS 2018, pp. 1-4. 2018.

[10] S. Abed, Y. Dwivedi, and M. Williams, "Consumers' Perceptions of Social Commerce Adoption in Saudi Arabia," in Proceedings 14th Conference on e-Business, e-Services and e-Society (I3E), 2015.

[11] E. Djafarova and C. Rushworth, "Exploring the credibility of online celebrities' Instagram profiles in influencing the purchase decisions of young female users," Comput. Human Behav., vol. 68, pp. 1-7, 2017.

[12] M. De Veirman, V. Cauberghe, and L. Hudders, "Marketing through instagram influencers: The impact of number of followers and product divergence on brand attitude," Int. J. Advert., vol. 36, no. 5, pp. 798828, 2017.

[13] Kaitlin Augustine (Civic Science), "Influencer Marketing," 2019. 
[14] L. V. Casaló, C. Flavián, and S. Ibáñez-Sánchez, "Influencers on Instagram: Antecedents and consequences of opinion leadership," J. Bus. Res., no. July, pp. 0-1, 2018.

[15] B. Godey et al., "Social media marketing efforts of luxury brands: Influence on brand equity and consumer behavior," J. Bus. Res., vol. 69, no. 12 , pp. $5833-5841,2016$.

[16] N. Hajli, "Social commerce constructs and consumer's intention to buy," Int. J. Inf. Manage., vol. 35, no. 2, pp. 183-191, 2015.

[17] M. J. M. Razi, M. Sarabdeen, M. I. M. Tamrin, and A. C. M. Kijas, "Influencing Factors of Social Commerce Behavior in Saudi Arabia," in Proceedings 2019 International Conference on Computer and Information Sciences (ICCIS), pp. 1-4, 2019.

[18] S. Sharma, P. Menard, and L. A. Mutchler, "Who to Trust? Applying Trust to Social Commerce," Journal of Computer Information Systems, vol. 59, no. 1. pp. 32-42, 2019.

[19] N. Hajli, J. Sims, A. H. Zadeh, and M. O. Richard, "A social commerce investigation of the role of trust in a social networking site on purchase intentions," J. Bus. Res., vol. 71, pp. 133-141, 2017.

[20] L. Esmaeili and S. A. Hashemi G, "A systematic review on social commerce,” J. Strateg. Mark., vol. 27, no. 4, pp. 317-355, 2019.

[21] L. Esmaeili, S. Mardani, M. Mutallebi, and S. Golpayegani, "Studying the Affecting Factors on Trust in Social Commerce," Int. J. Adv. Stud. Comput. Sci. Eng. IJASCSE, vol. 4, no. 6, 2015.

[22] E. Turban, J. Whiteside, D. King, and J. Outland, Introduction to Electronic Commerce and Social Commerce, Fourth edi. Springer, 2017.

[23] H. Han, H. Xu, and H. Chen, "Social commerce: A systematic review and data synthesis," Electronic Commerce Research and Applications, vol. 30. pp. 38-50, 2018.

[24] Socialize, "Social media and digital in Saudi Arabia: 2019 report," 2019.

[25] R. C. Mayer, J. H. Davis, and F. D. Schoorman, "An integrative model of organizational trust.” Acad. Manag. Rev., vol. 20, no. 3, pp. 709-734, 1995.

[26] S. Shi and W. S. Chow, "Trust development and transfer in social commerce: Prior experience as moderator," Industrial Management and Data Systems, vol. 115, no. 7. pp. 1182-1203, 2015.

[27] N. Hajli, Y. Wang, M. Tajvidi, and M. S. Hajli, "People, Technologies, and Organizations Interactions in a Social Commerce Era," IEEE Trans. Eng. Manag., vol. 64, no. 4, pp. 594-604, 2017.

[28] L. Chen and R. Wang, "Trust Development and Transfer from Electronic Commerce to Social Commerce: An Empirical Investigation," no. May, pp. 568-576, 2016.

[29] S. Farivar, Y. Yuan, and O. Turel, "Understanding Social Commerce Acceptance: The Role of Trust, Perceived Risk, and Benefit," Twentysecond Am. Conf. Inf. Syst., pp. 1-10, 2016.

[30] H. Hairudin, H. Mohamed Dahlan, M. H. Selamat, and A. R. Che Hussin, "Follower's quality factor in social commerce," J. Phys. Conf. Ser., vol. 1196, no. 1, 2019.

[31] D. Sirdeshmukh, J. Singh, and B. Sabol, "Consumer Trust, Value, and Loyalty in Relational Exchanges," J. Mark., vol. 66, no. 1, pp. 15-37, 2002.

[32] H. Alhulail, M. Dick, and A. Abareshi, "Factors that Impact Customers' Loyalty to Social Commerce Websites," in Proceedings International Conference on Information Resources Management (CONF-IRM), 2018.

[33] Ministry of Commerce and Investment, "'Maroof: an Initiative to Support e-Commerce in the Kingdom," 2018.

[34] C. Egger, "Identifying Key Opinion Leaders in Social Networks," TH Ko In - University of Applied Sciences Institute of Informatics, 2016.

[35] S. M. Aghdam and N. J. Navimipour, "Opinion leaders selection in the social networks based on trust relationships propagation," Karbala Int. J. Mod. Sci., vol. 2, no. 2, pp. 88-97, 2016.

[36] Y. WANG, "The Influence of Opinion Leaders towards Consumer Information Adoption in the Virtual Communities of Consumption," DEStech Trans. Soc. Sci. Educ. Hum. Sci., no. apme, pp. 444-451, 2017.
[37] A. Algi and I. Irwansyah, "KOL (Key Opinion Leader) as Consumer Trust Factor at Instagram Store," 2nd Indo IGCC, pp. 459-462, 2018.

[38] "What are KOLs? key opinion leader definition, examples \& more," mediakix. [Online]. Available: https://mediakix.com/blog/kols-keyopinion-leaders-definition-influencers/.

[39] Djmira and C. Rushwortafarova, Elh, "Exploring the credibility of online celebrities' Instagram profiles in influencing the purchase decisions of young female users," Comput. Human Behav., vol. 68, pp. $1-7,2017$.

[40] Hashoff, "Influencer marketer: A \#Hashoff state of the union report.," 2017.

[41] A. Algi and Irwansyah, "Consumer trust and intention to buy in Indonesia instagram stores," Proc. - 2018 3rd Int. Conf. Inf. Technol. Inf. Syst. Electr. Eng. ICITISEE 2018, pp. 199-203, 2019.

[42] V. A. Einarsdóttir, "From celebrities to the girl next door: Influencer marketing with a special focus on the social media platform, Instagram," University of Iceland, 2017.

[43] N. C. S. (NCS), "Sales Effect Study:Nielsen Catalina Solutions (NCS)," 2016.

[44] K. Sokolovaa and H. Kefia, "Instagram and YouTube bloggers promote it, why should I buy? How credibility and parasocial interaction in uence purchase intentions," J. Retail. Consum. Serv., 2019.

[45] E. L. Thorndike, "A constant error in psychological ratings," J. Appl. Psychol., vol. 4, no. 1, pp. 25-29, 1920.

[46] C. Lou and S. Yuan, "Influencer Marketing: How Message Value and Credibility Affect Consumer Trust of Branded Content on Social Media," Journal of Interactive Advertising, vol. 19, no. 1. pp. 58-73, 2019.

[47] X. J. Lim, A. R. bt Mohd Radzol, J.-H. (Jacky) Cheah, and M. W. Wong, "The Impact of Social Media Influencers on Purchase Intention and the Mediation Effect of Customer Attitude," Asian J. Bus. Res., vol. 7, no. 2, pp. 19-36, 2017.

[48] C. Liu, Z. Bao, and C. Zheng, "Exploring consumers' purchase intention in social commerce: An empirical study based on trust, argument quality, and social presence," Asia Pacific J. Mark. Logist., vol. 31, no. 2, pp. 378-397, 2019.

[49] R. De Maesschalck, D. Jouan-Rimbaud, and D. L. Massart, "The mahalanobis distance," Chemom. Intell. Lab. Syst., vol. 50, no. 1, pp. 1$18,2000$.

[50] J. F. Hair, M. Sarstedt, T. M. Pieper, and C. M. Ringle, "The Use of Partial Least Squares Structural Equation Modeling in Strategic Management Research: A Review of Past Practices and Recommendations for Future Applications," Long Range Plann., vol. 45, no. 5-6, pp. 320-340, Oct. 2012.

[51] R. Sekaran and R. Bougie, Research methods for business: A skill building approach, 7th ed. John Wiley \& Sons., 2016.

[52] G. W. Cheung and C. Wang, "Current approaches for assessing convergent and discriminant validity with SEM: issues and solutions," in Academy of Management Proceedings, vol. 2017, no. 1, p. 12706, 2017.

[53] W. W. Chin, A. Gopal, and W. D. Salisbury, "Advancing the Theory of Adaptive Structuration: The Development of a Scale to Measure Faithfulness of Appropriation," Inf. Syst. Res., vol. 8, no. 4, pp. 342 367, Dec. 1997.

[54] C. Fornell and D. F. Larcker, "Evaluating Structural Equation Models with Unobservable Variables and Measurement Error," J. Mark. Res., vol. 18, no. 1, p. 39, Feb. 1981.

[55] J. Hulland, "Use of partial least squares (PLS) in strategic management research: a review of four recent studies," Strateg. Manag. J., vol. 20, no. 2, pp. 195-204, Feb. 1999.

[56] B. Han and J. Windsor, "User's willingness to pay on social network sites," J. Comput. Inf. Syst., vol. 51, no. 4, pp. 31-40, 2011.

[57] H. Liu, H. Chu, Q. Huang, and X. Chen, "Enhancing the flow experience of consumers in China through interpersonal interaction in social commerce," Comput. Human Behav., vol. 58, pp. 306-314, 2016. 